\title{
Relação Lazer/Trabalho e Atitude diante das Problemáticas Ambientais Contemporâneas: desafios para a atuação profissional com o ecoturismo
}

\author{
César Teixeira Castilho \\ Christianne Luce Gomes ${ }^{b}$
}

\section{Resumo}

O objetivo deste artigo é discutir a atuação de profissionais que trabalham com ecoturismo no entorno de Belo Horizonte e prestam serviços em quatro ramos de atividades de lazer: mountain bike, escalada, observação de vida selvagem e trekking de longa duração. A investigação foi impulsionada pelas seguintes indagações: de que maneira a relação trabalho/lazer é configurada na atuação desses profissionais? Quais aspectos são abordados em seus discursos e práticas profissionais quando se pensa na consciência ambiental e na degradação do meio ambiente? A metodologia desta investigação qualitativa envolveu pesquisa bibliográfica e de campo, na qual os dados foram coletados por meio da observação participante e entrevistas semiestruturadas com quinze profissionais. Os resultados evidenciaram que os profissionais entrevistados iniciam uma aproximação com atividades na natureza por meio da influência familiar, e que, ao longo do tempo, aquilo que outrora era considerado lazer torna-se profissão. Posteriormente, um melhor aprimoramento técnico é buscado a fim de que se obtenha a profissionalização da área. A busca pelo "risco" exerce influência na preferência pelas experiências de lazer em meios naturais e, nesse aspecto, a natureza é relegada a um segundo plano. Embora também sejam passíveis de críticas, os profissionais que atuam em atividades como a observação de vida selvagem e trekking de longa duração evidenciaram uma maior sensibilidade quanto às questões ecológicas e maior influência na educação ambiental dos praticantes.

Palavras-chave: Ecoturismo; Lazer; Atuação profissional.

\begin{abstract}
Work-leisure relation and attitude before the contemporary environmental issues: challenges for the professional performance with ecotourism

This article aims at discussing the performance of professionals that work with ecotourism in the surrounding area of Belo Horizonte and render services in four leisure activities: mountain biking, rock climbing, wildlife viewing and trekking. The investigation was impelled by the following questions: how the work-leisure relation is configured in these professionals' performance? Which aspects are approached in their discourses and professional performance in relation to the environmental consciousness and environment degradation? The methodology of this qualitative investigation involved bibliographic and field research, in which the data were collected through participant
\end{abstract}

a. Doutor em "Sciences du Sport et du Mouvement Humain" pela Univerdade de Paris-Sud (Paris 11), Pesquisador de pós-doutorado no Programa de Pós-Graduação Interdisciplinar em Estudos do Lazer pela Universidade Federal de Minas Gerais (UFMG). E-mail: castcesarster@gmail.com

b. Doutora em Educação pela UFMG com Pós-Doutorado em Ciências Políticas e Sociais pela Universidade Nacional de Cuyo, Argentina. Docente da UFMG, pesquisadora do CNPq (Produtividade em Pesquisa) e da Fapemig (PPM). Líder dos Grupos de Pesquisa LUCE e OTIUM (UFMG/CNPq). E-mail: chris@ufmg.br 
observation and semistructured interviews with fifteen professionals. The results evidenced that the interviewed professionals approach nature-based activities due to family influence and, over the years, what was considered leisure turns into profession. Later, a better technical improvement is sought in order to obtain the professionalization in the area. The search for "risk" influences the preference of leisure experiences in natural environment and, in this aspect, nature comes second. Although they are also subject to criticism, the professionals that work with activities as wildlife viewing and trekking evidenced a greater sensibility regarding ecological questions and greater influence on the environmental education of the practitioners.

Keywords: Ecotourism; Leisure; Professional Performance.

\section{Resumen}

Relación ocio/trabajo y la actitud ante a los problemas ambientales contemporáneos: desafíos para la actuación profesional en el ecoturismo

Este estudio tiene como objetivo analizar el trabajo de los profesionales que actúan con el ecoturismo en los alrededores de la ciudad de Belo Horizonte y que prestan servicios en cuarto ramas de actividades de ocio: ciclismo de montaña, escalada, observación de la fauna y trekking de larga duración. Las preguntas que guiaron esta investigación fueron: ¿Cómo se establece la relación de trabajo/ocio en el desempeño de estos profesionales? ¿Cuáles son los aspectos sobre la conciencia ambiental presentes en el discurso y en las prácticas de estos profesionales? La metodología aplicada en este estudio se basa en un enfoque cualitativo. Los datos fueron recogidos a través de observación participante y entrevistas, involucrando a quince profesionales. Los resultados mostraron que los profesionales que trabajan en las actividades de turismo en la naturaleza empiezan un acercamiento a estas experiencias a través de la influencia de la familia. Con el transcurso del tiempo, lo que antes era considerado ocio se convierte en profesión. Más tarde, buscan mejorar técnicamente para perfeccionar la práctica profesional. La búsqueda del "riesgo" parece tener influencia en la preferencia por experiencias de ocio en la naturaleza y, muchas veces, la naturaleza se ve relegada a un segundo plano. A pesar de que también están abiertos a la crítica, los profesionales que trabajan en actividades como la observación de la fauna y trekking de larga duración mostraron mayor sensibilidad en temáticas relativas al medioambiente y una mayor influencia en la educación ambiental de los practicantes.

Palabras clave: Ecoturismo; Ocio; Desempeño Profesional.

\section{CONSIDERAÇÕES INICIAIS: FUNDAMENTANDO A TEMÁTICA INVESTIGADA}

Apesar das especificidades do turismo e do lazer em termos de desenvolvimento teórico-conceitual, políticas, mercado e intervenções, as duas áreas apresentam interfaces e estão intimamente relacionadas. Alguns autores, como Camargo (2001), Moesch (2002) e Rejowski (2010), por exemplo, consideram que turismo e lazer são áreas multidisciplinares com tênues fronteiras, sendo relevante sistematizar conhecimentos e pesquisar articulações entre elas, superando abordagens isoladas, parciais e dicotômicas.

Entretanto, esse tipo de preocupação ainda é incipiente no contexto acadêmico, pois, em geral, o lazer é pouco discutido tanto na graduação como na pós-graduação em Turismo (BERNARDINO; ISAYAMA, 2006; FARIA, 2012; GOMES et al., 2008; SOUZA, 2011; TAVEIRA; GONÇALVES, 2012), sendo escassos os avanços teórico-práticos nesse âmbito. 
Embora seja comum encontrar classificações que restrinjam o lazer a um segmento do turismo, e mesmo que as motivações das viagens turísticas possam ser diversificadas, Coriolano (2006) salienta que a essência do turismo é o lazer e a viagem. Por isso, no entendimento dessa autora, seria "redundância falar de turismo de lazer". (CORIOLANO, 2006, p. 43)

Panosso Netto (2010, p. 18) discorda desse tipo de interpretação, mas destaca que o turismo é um setor diversificado, "que está estreitamente relacionado com viagens, eventos, lazer, hospitalidade, hospedagem, economia, cultura, meio ambiente, entretenimento, recreação, entre outras áreas". Por reconhecer essa multiplicidade de possibilidades e enfoques, o autor adverte que a compreensão do turismo não pode ser feita de forma isolada, visão com a qual concordamos. Pensar de acordo com essa visão integrada foi um dos principais desafios desta pesquisa, que procurou contribuir com a produção de conhecimentos sobre o turismo e o lazer na perspectiva da atuação profissional em áreas naturais.

Com relação às concepções que fundamentam a temática aqui investigada, o lazer é um direito social formalmente reconhecido na Constituição Federal do Brasil de 1988, sendo citado nos artigos 6ํㅜ 7으, 217으 e 227으 (GOMES; ISAYAMA, 2015). 0 lazer é aqui compreendido como uma necessidade humana e como uma dimensão da cultura, caracterizada pela vivência lúdica de manifestações culturais no tempo/espaço social (GOMES, 2014). Essa necessidade concretiza-se na ludicidade e pode ser satisfeita de múltiplas formas, segundo os valores e interesses dos sujeitos, grupos e instituições em diferentes contextos históricos, políticos, socioculturais e ambientais. Ainda de acordo com Gomes (2014), o lazer representa a necessidade de fruir, ludicamente, as incontáveis práticas sociais constituídas culturalmente, entre as quais pode-se destacar o turismo.

0 turismo é concebido, neste artigo, conforme a interpretação de Gastal e Moesch (2007): para as autoras, o turismo diz respeito ao deslocamento de pessoas em tempos/espaços diferentes dos habituais, o que está repleto de subjetividade e contempla o afastamento do cotidiano, possibilitando ao sujeito um "estranhamento" quanto à experiência vivida. Por meio de interações entre visitantes e comunidades locais, o turismo pode mobilizar a (re)descoberta de cores, formas, texturas, cheiros, sabores, sentidos e significados em um contínuo processo de partilha.

Uma das possibilidades do turismo que vem crescendo substancialmente nas últimas décadas é o ecoturismo, também chamado de turismo ecológico. Segundo Serrano (1997), essa prática surgiu como contraponto ao turismo massivo, estandardizado e predatório, tendo em vista defender a proposição de roteiros personalizados, minimizar os impactos da atividade turística e ampliar a consciência ambiental. Nessa perspectiva, o ecoturismo busca atender aos interesses paisagístico-ecológicos das pessoas interessadas, possibilitando-lhes desenvolver variadas atividades de lazer na natureza. De acordo com Ceballos-Lascurain (1990 apud PELLEGRINI FILHO, 1993, p. 138):

O ecoturismo consiste em viagens por áreas naturais não degradadas ou não poluídas, com o objetivo específico de estudar, admirar e fruir a paisagem e suas plantas e animais, tanto quanto manifestações culturais (do passado e do presente) encontradas nessas áreas. Nesses termos, o turismo orientado para a natureza implica uma colocação científica, estética ou filosófica [...]. 0 ponto específico é que a pes- 
soa que pratica ecoturismo tem a oportunidade de mergulhar na natureza de uma maneira normalmente não possível no meio ambiente urbano.

Serres (2004) considera que o conceito de "natureza" faz referência ao mundo como um todo, exceção feita às transformações realizadas pelo ser humano. Nesse sentido, tal concepção inclui o universo, os fenômenos naturais, as florestas e outros ambientes, plantas e seres vivos. 0 ser humano, sendo ele mesmo um ser vivente, encontra-se igualmente inserido nessa compreensão. Neste estudo, pretende-se compreender a natureza por uma concepção ampla, valorizando sua singularidade e sua importância na constituição do planeta. Como descrito por Jamal et al. (2003, p. 3, tradução nossa), a natureza "é muito mais um marcador ideológico do que algo real, pois a compreensão sobre natureza está profundamente incorporada nas influências geopolíticas e culturais, com significados simbólicos, construções sociais e influências históricas". ${ }^{1}$

No Brasil, um documento de referência denominado "Diretrizes para uma Política Nacional de Ecoturismo" esclarece que o ecoturismo engloba "o patrimônio natural e cultural, incentiva sua conservação e busca a formação de uma consciência ambientalista através da interpretação do ambiente, promovendo o bem-estar das populações envolvidas" (BRASIL, 1994).

Wearing e Neil (2001) identificam quatro elementos fundamentais do ecoturismo: a) a noção de movimento ou viagem de um lugar a outro; b) a natureza como base para a escolha do destino; c) o incentivo à conservação do meio ambiente, abarcando inclusive as populações locais (sua cultura, necessidades, identidades) e d) o papel educativo, subsídio para o tópico anterior.

Conforme lembra Panosso Netto (2010, p. 94):

Não é à toa que um dos segmentos que mais cresce é o ecoturismo, aquele turismo feito em áreas naturais com consciência da importância da preservação ambiental. A busca por paisagens originais, ou pouco modificadas, tem crescido a níveis nunca antes vistos.

Há que se destacar, todavia, a proliferação de discursos ingênuos, idealizados e glamorizados acerca do ecoturismo, pois muitas iniciativas não condizem com os princípios defendidos. Nesses casos predomina o consumo hedonista da natureza como se esta fosse um cenário propício às aventuras dos interessados (PIMENTEL, 2009). Além disso, persistem discursos e práticas equivocadas, gerando descrédito quanto à sustentabilidade divulgada pelo ecoturismo. Sobre essa questão, Seabra (2001, p. 9) afirma que o caráter sociodesenvolvimentista do ecoturismo é amplamente destacado em projetos oficiais e discursos políticos, mas dificilmente alcança e envolve "as comunidades tradicionais que habitam as unidades de conservação, sendo estas tragadas por uma política oficial massificante, travestida de autossustentável".

Mesmo com essas ressalvas, o ecoturismo é um campo abrangente e, de acordo com Serrano (2000), abarca uma multiplicidade de atividades de lazer vivenciadas em áreas naturais, entre as quais podem ser citadas: trekking, hiking,

1. Original: "is as much an ideological marker as it is something real, for understandings about nature are deeply embedded in geopolitical and cultural influences, symbolic meanings, social constructions and historical influences". 
escaladas, rapel, espeleologia, mountain bike, cavalgadas, mergulho, rafting, floating, kayaking, vela, voo livre, paragliding, balonismo, estudos do meio, safári fotográfico, observação de fauna e de flora, pesca (catch-release), turismo esotérico e turismo rural, entre outras.

Levando-se em conta a relevância de aprofundar conhecimentos sobre essa temática, foi realizada uma pesquisa que elegeu como objeto de estudo a atuação de profissionais que trabalham com ecoturismo no entorno de Belo Horizonte, prestando serviços em quatro ramos de atividades de lazer: mountain bike, escalada, observação de vida selvagem e trekking de longa duração. A investigação foi impulsionada pelas seguintes indagações: de que maneira a relação trabalho/ lazer é configurada na atuação desses profissionais? Quais aspectos são abordados em seus discursos e práticas profissionais quando se pensa na consciência ambiental e na degradação do meio ambiente?

As empresas e profissionais selecionados para a pesquisa prestam serviços no ramo do ecoturismo e organizam viagens, excursões ou passeios ${ }^{2}$ para pequenos grupos em áreas naturais no entorno de Belo Horizonte, o que envolve uma incipiente infraestrutura turística composta por meios de hospedagem, transporte, restaurantes, programações e atividades de lazer, visitas guiadas, passeios, seguro-viagem etc. Barreto (2000, p. 21) assinala que os serviços turísticos não têm razão de ser "sem um recurso que sirva de base para transformá-lo em atrativo e sem turistas que o visitem."

Apesar das especificidades de atuação dos profissionais do diversificado campo do ecoturismo, neste artigo optou-se por denominá-los de modo amplo como "profissionais de lazer na natureza" (CASTILHO, 2013). Procurando contribuir para ampliar as discussões que aproximam o turismo e o lazer, a pesquisa realizada seguiu os encaminhamentos metodológicos detalhados a seguir.

\section{METODOLOGIA}

A pesquisa qualitativa, que visa compreender a lógica interna de grupos, instituições e atores, foi escolhida com o objetivo de aproximar as pesquisadoras das interpretações pertinentes no que tange a: "(a) valores culturais e representações sobre história e temas específicos; (b) relações entre indivíduos, instituições e movimentos sociais; (c) processos históricos, sociais e de implementação de políticas públicas e sociais" (MINAYO, 2010, p. 23).

Dessa forma, foram combinadas as pesquisas bibliográficas e de campo. Segundo Laville e Dionne (1999, p. 112), a pesquisa bibliográfica consiste em "revisar todos os trabalhos disponíveis, objetivando selecionar o que possa servir para sua pesquisa". Contudo, as autoras lembram que toda pesquisa tem um foco de interesse, e, para que não se perca de vista a pergunta central, propõem a elaboração de "bibliografias temáticas". Com base nessa ideia, foram enfatizados os

2. De acordo com Panosso Netto (2010, p. 52), o visitante temporal que fica menos de 24 horas no destino visitado é considerado um excursionista. 0 turista, embora também seja um visitante, permanece mais de 24 horas no destino, com pernoite no local. "É a pessoa que está em viagem e que destina parte de seu tempo livre para atividades de recreação, entretenimento, lazer, enriquecimento cultural, entre outras." 
seguintes tópicos na fundamentação bibliográfica: atuação profissional em lazer, turismo, ecoturismo, lazer na natureza e estudos sobre a contemporaneidade.

Para delimitar o campo a ser pesquisado por meio de observações e entrevistas, inicialmente realizou-se uma triagem de possíveis empresas e/ou profissionais que possuíam histórico de atuação com ecoturismo na cidade de Belo Horizonte e arredores. Após esse levantamento, a escolha pelo objeto pesquisado seguiu os seguintes critérios: (1) ter experiência e atuação na área há pelo menos cinco anos; (2) organizar viagens e excursões para pequenos grupos com o objetivo de vivenciar atividades de lazer na natureza; (3) conceder anuência formal para a realização da pesquisa; (4) estar sediado na cidade de Belo Horizonte e/ ou arredores; (5) atuar com ecoturismo no estado de Minas Gerais.

Após o processo de triagem de empresas e profissionais do ramo, foram selecionados: uma agência especializada em passeios de mountain bike com sede na cidade de Belo Horizonte; uma escola de escalada que desenvolve atividades em todas as regiões do estado de Minas Gerais; uma empresa especializada em observação de vida selvagem sediada em Belo Horizonte e que promove excursões não apenas em Minas Gerais, mas também em diversos outros estados e países (sobretudo na América do Sul); e dois guias locais de trekking de longa distância que atuam no vilarejo Lapinha da Serra. ${ }^{3}$

Segundo Laville e Dionne (1999, p. 176), a observação pode ser considerada como um "privilegiado modo de contato com o real: é observando que nos situamos, orientamos nossos deslocamentos, reconhecemos as pessoas, emitimos juízos sobre elas". A escolha pela observação participante permite uma maior interação na vida de um grupo para compreender o seu sentido interno; porém, é sabido que nesse método o observador deve mostrar-se ainda mais metódico para não perder informações importantes para sua pesquisa.

Com o intuito de realizar o trabalho de campo, particularmente a observação participante, foram realizadas as seguintes atividades de ecoturismo com as empresas e profissionais: dois passeios de mountain bike na cidade de São Gonçalo do Bação ${ }^{4}$, três excursões de atividade de escalada outdoor na região de Lagoa Santa ${ }^{5}$, especificamente no Sítio do $\operatorname{Rod}^{6}$, duas viagens voltadas para observação de pássaros na região da Serra do Cipó 7 e um trekking de longa distância entre os vilarejos Lapinha da Serra e Tabuleiro sob a condução de guias locais de turismo.

Os passeios de mountain bike oferecidos pela empresa pesquisada acontecem normalmente aos finais de semana e possuem uma duração média de dez horas. A atividade é bem popular na cidade de Belo Horizonte e arredores, onde o relevo e a natureza favorecem esse tipo de prática esportiva. 0 grupo era composto de aproximadamente quinze pessoas e a presença do pesquisador foi informada previamen-

3. Lapinha da Serra: vilarejo pertencente ao distrito de Santana do Riacho. Está localizado a aproximadamente duas horas da cidade de Belo Horizonte.

4. São Gonçalo do Bação: cidade localizada a $70 \mathrm{~km}$ de Belo Horizonte, no distrito de Itabirito.

5. Lagoa Santa: é um município brasileiro do estado de Minas Gerais, localizado na região metropolitana de Belo Horizonte.

6. Sítio do Rod: área criada há 15 anos visando fomentar e dar suporte a esportes ligados à natureza, tais como escalada esportiva em rocha, mountain bike, trekking e espeleoturismo.

7. Serra do Cipó: localiza-se a 90 quilômetros a nordeste de Belo Horizonte, na região sul da Cordilheira do Espinhaço, entre os paralelos 19 e $20^{\circ} \mathrm{S}$ e 43 e $44^{\circ} \mathrm{W}$, no divisor de águas das bacias hidrográficas dos rios São Francisco e Doce. Local de grande apelo ecoturístico do estado de Minas Gerais 
te pelos profissionais responsáveis. Dois passeios com grupos distintos foram observados, o que possibilitou uma análise mais ampla da atuação dos profissionais.

A escalada outdoor também acontece aos finais de semana e funciona como um complemento aos treinamentos realizados dentro da escola de escalada situada em Belo Horizonte. As viagens são planejadas pelos profissionais em regiões próximas da cidade e podem durar até três dias. 0 número de pessoas varia de acordo com os objetivos e os locais escolhidos, mas, normalmente, não ultrapassa dez participantes.

No que concerne à empresa especializada em "observação de vida selvagem", houve participação em duas viagens realizadas na região da Serra do Cipó, que tinham como objetivo a observação de aves. ${ }^{8}$ Esse tipo de observação é o mais requisitado dentro da empresa selecionada e tem como principal público turistas estrangeiros, principalmente norte-americanos e europeus. Visto que a observação de pássaros permanece desconhecida pela maioria da população brasileira, a procura por tal atividade de lazer é maior entre pessoas de outros países.

As viagens foram realizadas junto de um grupo de quatro pessoas e houve concordância prévia quanto à presença do pesquisador. A observação de pássaros é uma modalidade estritamente voltada para o lazer e, diferentemente dos ornitologistas, que buscam uma compreensão científica por meio da aproximação com os animais, os apreciadores da atividade querem simplesmente observar e desfrutar o momento, considerando-a como um hobby.

A observação realizada no vilarejo Lapinha da Serra deu-se pela participação em um trekking de longa distância, que dura três dias e acontece nas trilhas históricas entre as cidades de Lapinha da Serra e Tabuleiro. A presença de guias locais é essencial, visto que o caminho possui diversas nuances e exige um conhecimento prévio. 0 grupo era composto por cinco turistas e dois guias pertencentes à comunidade local.

O número de entrevistados foi definido ao longo da pesquisa de campo, procurando contemplar todos os sujeitos envolvidos nas atividades observadas. 0 parâmetro utilizado para o dimensionamento da quantidade de entrevistas seguiu o critério de saturação, entendido como "o conhecimento formado pelo pesquisador, no campo, de que conseguiu compreender a lógica interna do grupo ou da coletividade em estudo" (MINAYO, 2010, p. 197). Cabe esclarecer que os quinze profissionais selecionados possuem formações em áreas e níveis diversos: em termos de escolaridade, dois guias locais têm formação básica fundamental e realizaram cursos de capacitação para atuarem como guias de turismo; os demais têm curso superior em diferentes áreas do conhecimento: Turismo, Educação Física, Biologia e Engenharia Florestal. É importante ressaltar que todos realizaram formação complementar em turismo e temas afins, visando qualificar sua inserção e atuação profissional na área.

0 roteiro das entrevistas foi elaborado levando em consideração as práticas dos profissionais pesquisados e, essencialmente, a relação constituída entre eles e os visitantes no decorrer da viagem, excursão ou passeio. Os voluntários estavam cientes da utilização de gravador na captação dos depoimentos. 0 uso do equipamento foi adotado conforme considerações de Zago (2003), para quem a

8. Observação de pássaros é uma atividade com intuito exclusivamente recreativo. Pode ser realizada a olho nu, ou através de equipamentos como binóculos ou telescópio. Muitas vezes, o simples escutar do canto já pode ser considerado uma observação de aves (MOSS, 2005). 
gravação do material permite maior liberdade ao pesquisador na condução das questões, no estabelecimento da relação de interlocução e no avanço da problematização. Posteriormente, todos os depoimentos foram transcritos. Esses registros auxiliaram a organização e análise dos resultados pelo acesso a um material mais completo e que poderia ser reexaminado a qualquer momento.

A análise de conteúdo foi a técnica utilizada na interpretação das informações coletadas. Essa estratégia metodológica de tratamento da informação pode ser caracterizada como um recurso para compreender o processo de constituição das percepções, atitudes e representações de grupos específicos, com a vantagem de permitir uma comparação sistemática de dados. Seu princípio é desmontar a estrutura e os elementos do conteúdo estudado para esclarecer suas diferentes características e extrair sua significação (LAVILLE; DIONNE, 1999).

Em um primeiro momento, logo após o trabalho de campo, foi feita uma pré-análise de todo o material recolhido. Depois de agrupado e analisado o material, chegou-se às seguintes categorias: perfil dos profissionais, formação acadêmica, consciência ambiental e degradação ambiental relacionada às modalidades pesquisadas. A partir da escolha das categorias de análise, novas leituras do material de campo foram realizadas e reagrupadas de acordo com o tema e o sentido que expressavam. É nesse momento que as análises mais criteriosas se iniciam e o diálogo com a teoria torna-se imprescindível para fundamentar a discussão.

As atividades pesquisadas podem ser congregadas em dois subgrupos, de acordo com a motivação dos indivíduos: subgrupo da "teoria do risco" e subgrupo da "teoria do autoconhecimento" (CASTILHO, 2013; WALLE, 1997). Embora as duas teorias não abordem de maneira ampla todas as possibilidades que integram o ecoturismo, optou-se por tal divisão porque as atividades de lazer estudadas possuem algumas peculiaridades que possibilitam essa associação.

No que diz respeito à teoria do risco, pode-se dizer que o mountain bike e a escalada outdoor são similares quanto à procura por uma atividade relacionada à aventura, à velocidade e ao desafio contra e na natureza. Observou-se que os visitantes que apreciam essas atividades valorizam a disputa de desafios, abundantes nessa prática. São atividades predominantemente físicas e, mesmo quando encaradas de maneira lúdica, englobam algum tipo de competição.

A observação de vida selvagem e o trekking de longa distância assemelham-se pelo aspecto contemplativo e pela busca de uma interação maior com o ambiente natural. Segundo Walle (1997, p. 857), "certas atividades, tais como observação de aves e pesca esportiva, são denominadas através da intuição ou pela compreensão da consciência e pela busca do conhecimento." ${ }^{10}$ Essa reflexão pode proceder de uma contemplação intelectual da natureza (EMERSON, 1836) ou pode ser direcionada a uma preservação vulnerável da natureza (ARNOULD et al., 1998). O sentido da observação da vida selvagem é o lazer contemplativo, enquanto o trekking de longa distância reflete interessantes aspectos relacionados ao ecoturismo e à sociabilidade.

9. Traduzido dos termos em inglês Risk Theory and Insigth Theory (WALLE, 1997).

10. Traduzido do original: "That certain nature-based activities, such as Bird-watching and fly-fishing, are dominated by intuitive or conscious insight and knowledge seeking." 
É importante salientar que a coleta de dados só foi iniciada após a aprovação do Projeto de Pesquisa e do Termo de Consentimento Livre e Esclarecido pelo Comitê Nacional de Ética em Pesquisa (Conep) do Ministério da Saúde do Governo do Brasil e pelo Comité de Ética da UFMG. A pesquisa está registrada no Conep pelo número 01396612.1.000.5149.

\section{TRABALHO E LAZER NA NATUREZA: DUAS FACES DE UMA MESMA MOEDA?}

Embora a atuação profissional tenha sido pesquisada considerando o desenvolvimento de distintas atividades de lazer na natureza, foi possível identificar algumas características comuns dos profissionais envolvidos.

0 primeiro aspecto comum identificado nos depoimentos dos entrevistados é a proximidade com a natureza despertada desde a infância. Os relatos convergem no que diz respeito a uma influência importante da família nos primeiros contatos com as modalidades de lazer na natureza, com o gosto pelas viagens ao redor de Belo Horizonte (principalmente à Serra do Cipó) e com o despertar de um novo elo entre trabalho e lazer na fase adulta. Nesse sentido, mais do que uma mudança com relação ao tempo e/ou ao espaço, a discussão aproxima-se de uma transmutação de comportamento, uma nova relação com a profissão.

Nos trechos descritos a seguir, fica claro como a relação com o meio natural foi se solidificando ao longo da vida de cada entrevistado:

Eu comecei o meu contato com este tipo de atividade através da minha família mesmo. [...] Meus avós moravam no interior, e nos finais de semana havia aquela ida para o sítio, para casa do meu avô. Meu pai é de Aimorés, quase Espírito Santo, e minha mãe é de Campo das Vertentes, próximo a Congonhas. E, nesse local, sempre tinham essas atividades, como andar a cavalo, fazer alguma caminhada para ir a algum lugar, meu pai sempre incentivou a bicicleta, desde pequeno, todo mundo tinha e levávamos para pedalar lá. Assim, eu fui me acostumando com este convívio com a natureza. Minha tia também, quando eu tinha oito anos, começou a me levar para acampar na Serra do Cipó, ainda eram áreas abertas, não havia áreas de camping. (Entrevistado 4)

Eu morava em Nova Lima [região metropolitana de BH] e sempre tive uma relação muito estreita com o meio ambiente. Morava em um condomínio, com muita mata perto, e gostava muito disso. 0 meu primeiro contato com fotografia foi por intermédio do meu avô. Eu logo tive acesso a uma câmera e fui sempre fotografando bichos, plantas, paisagens e, com esse gosto, fui desenvolvendo esse hobby profissionalmente. (Entrevistado 2)

Em alguns momentos, durante o trabalho de campo, foi difícil definir até que ponto os profissionais discorriam sobre o próprio trabalho e suas atuações, e até que ponto comunicavam sobre alguma atividade lúdica pela qual têm grande afinidade, ou seja, o seu próprio hobby. Embora tenham responsabilidades e preocupações semelhantes às de outros profissionais (por exemplo, controle do risco e das emoções), foi constatada a inexistência de uma fronteira rígida entre o trabalho e o lazer, conforme salientado por Stebbins (2014). 
Uma característica primária é a distinta relação com o tempo estabelecida por esses sujeitos, quando se tem como referência o cidadão contemporâneo. As viagens organizadas por esses profissionais possuem durações diversas, podendo ser caraterizadas como não lineares, ou seja, nenhuma viagem é similar à outra. Além disso, como relatado nas entrevistas, durante o período de férias eles praticam as mesmas atividades com as quais atuam profissionalmente ou alguma outra que abarque o lazer na natureza.

As pessoas que fazem parte desse negócio normalmente são praticantes da atividade. Igual eu sou, meu sócio também. [...] Gostamos de mato, vamos dizer assim. Quando estamos livres, somos praticantes da modalidade. Não é por acaso que escolhemos uma profissão voltada para o turismo. (Entrevistado 1)

Eu sempre pratiquei montanhismo, trekking, caminhada, fiz vários acampamentos ao longo da minha vida, sempre tive mountain bike, desde 1993, que foi quando eu comprei a minha primeira bike. Então, eu sempre fui um entusiasta das atividades ao ar livre. (Entrevistado 3)

A análise da atuação desses profissionais permite novas acepções teóricas que confrontam a antiga dicotomia entre trabalho e lazer presente nos estudos sobre a temática principalmente na segunda metade do século XX. Embora a contemporaneidade já seja caracterizada por novas configurações trabalhistas - tanto em relação ao tempo quanto em relação ao espaço -, ainda há visões dualísticas na sociedade e nas próprias pesquisas que abordam o lazer contemporâneo.

Os estudos precursores de Veblen (1899), publicados no final do século XIX, e de Dumazedier (1967), por exemplo, são categóricos na divisão de dois tempos distintos: um voltado para o trabalho e outro voltado para o lazer, este último conhecido como tempo livre. Essa liberdade aparente era vista como uma conquista do cidadão daquela época, que vislumbrava um descanso merecido das atividades laborais. De acordo com as explanações de Veblen (1899), quanto mais as sociedades se tornassem sofisticadas e modernas, menor seria o tempo dispendido para a sobrevivência básica e mais tempo seria disponibilizado para as atividades complexas de consumo. Assim, o desenvolvimento societário permitiria um maior tempo livre aos cidadãos, principalmente àqueles que fossem detentores de capital. No entanto, como descrito por Schor (1992) e Gershuny (2000), o tempo de trabalho, contrariamente às previsões, aumentou substancialmente nos últimos cinquenta anos, da mesma forma que a produtividade tem se desenvolvido de maneira sem precedentes.

No contexto atual, torna-se possível superar a dicotomia entre trabalho e lazer analisando o fenômeno a partir da possibilidade de se exercer uma profissão na qual ambos se fundem. De acordo com os estudos de Beatty e Torbert (2003), centralizados na atuação de guias de turismo, trabalho e lazer estão relacionados e podem ser experimentados ao mesmo tempo; além disso, essa experiência torna-se uma habilidade que necessita ser desenvolvida e cultivada como um indicador de desenvolvimento pessoal. De acordo com os autores, é primordial que algumas atividades sejam consideradas trabalho e lazer, e o problema não está somente relacionado ao tempo (muito tempo dispendido para o trabalho) ou à atividade (opções de lazer); mais do que isso, o problema maior está na atitude do profissional em relação a sua atividade. 
Stebbins (2014, p. 43) colabora com essa discussão quando esclarece que "o trabalho e o lazer, ao contrário do conhecimento convencional, não são nem totalmente separados, tampouco esferas mutuamente antagônicas da vida moderna."

Duncan (2009) apresenta um estudo de caso no qual os trabalhadores temporários não medem seus esforços quanto à mobilidade, trabalho e lazer para não se distanciarem das vivências que são vistas como prioritárias em suas vidas. Dessa forma, adaptam todos os parâmetros de suas vidas para não se apartarem das atividades de lazer que fomentam essa paixão. Além disso, Duncan (2009) sugere que a relação entre lazer, trabalho e viagem é mais complexa nos dias atuais do que em outros períodos, pois a adição do elemento viagem amplifica essa equação.

Todas as atividades de lazer que integram o ramo do ecoturismo podem viabilizar uma "fuga" dos centros urbanos, uma vez que os espaços naturais nesses ambientes de concreto são escassos (CARNICELLI-FILHO, 2010; LIMA, 2016). Ademais, alguns autores (BRUHNS, 2010; BRUHNS; MARINHO, 2012; TELES, 2011) chamam atenção para outros aspectos relevantes nesse contexto, tais como o anseio de estabelecer uma relação mais próxima com a natureza, muitas vezes idealizada, bem como a busca por experiências com risco controlado. Assim, para esses pesquisadores, trabalho, lazer e viagem andam juntos e não possuem barreiras definidas. Sobre essa temática, alguns trechos das entrevistas apontam para a mesma direção:

Quando eu comecei a trabalhar com turismo, minha "onda" era viajar de graça. Meu pai sempre viajou muito e sempre nos levou para viajar com ele. Com certeza, herdei essa característica dele. Eu sempre queria viajar, sempre era a pessoa responsável pela organização das viagens com os meus amigos. Serra do Cipó a gente ia quase que todo final de semana. E, na maioria das vezes, era eu que organizava tudo, comprava e depois dividia as contas. (Entrevistado 2)

Como escalador, eu já visitei vários países, já conheci várias pessoas. Um dos aspectos mais interessantes dessa profissão, além da prática de uma modalidade, é a possibilidade de viajar e conhecer novas pessoas. Acabei de chegar da Patagônia, ficamos quase dois meses na região do Fitz Roy [montanha da região]. (Entrevistado 4)

Complementando as ideias anteriores, Carnicelli-Filho (2010) realizou um estudo com guias de rafting que, embora tenham suas obrigações e responsabilidades bem definidas pela empresa que representam, conseguem combinar o lazer, o trabalho, a amizade, os compromissos e a hierarquia em um mesmo ambiente onde, normalmente, o interior de suas personalidades está refletido. Esse estudo revela implicações interessantes no conhecimento da complexidade existente entre lazer, trabalho e estilo de vida.

É nessa perspectiva, segundo a qual o trabalho e o lazer se mesclam e se confundem a todo instante, que as análises de campo foram realizadas. Uma evidente relação entre os profissionais que participaram do estudo e as atividades de lazer por eles oferecidas foi detectada, conforme destacado nos depoimentos. Esta caraterística de amor e afinidade pela profissão poderia ser algo mais corriqueiro na sociedade brasileira, que ainda favorece áreas de atuações tidas como "bem vistas" ou "mais bem remuneradas". O pré-requisito para a escolha de uma profissão não deveria se sobrepor à paixão e, quando possível, deveria estar bem próximo ao lazer de cada um. 
Em suma, foi constatado que as fronteiras entre trabalho e lazer são tênues para os profissionais pesquisados, o que está de acordo com estudos contemporâneos sobre essa temática (GOMES, 2014). Embora os sujeitos da pesquisa assumam responsabilidades profissionais, o trabalho exercido está diretamente correlacionado ao lazer. Assim, não foi possível identificar até que ponto as experiências realizadas na natureza são trabalho ou lazer, pois a ludicidade está muito presente e atravessa a atuação profissional desses guias de turismo, revelando as relações fronteiriças entre os dois campos. Isso não quer dizer que haja irresponsabilidade, descompromisso ou espontaneísmo: ao contrário, observou-se o profissionalismo em diversas situações, especialmente no que se refere à segurança e infraestrutura.

\section{DISCURSOS E PRÁTICAS DOS PROFISSIONAIS SOBRE OS DESAFIOS AMBIENTAIS}

Como mencionado, os profissionais que participaram do estudo têm formações diversas e, de maneira unânime, criticaram a não inclusão de preceitos básicos durante os cursos realizados para uma melhor atuação nas experiências de lazer na natureza. Eles enfatizaram que a busca por um maior conhecimento da área ou até mesmo por um primeiro contato aconteceu "fora dos muros" universitários. Cursos de graduação em Turismo, Educação Física e Biologia, por exemplo, poderiam explorar conteúdos que abordassem criticamente esses conhecimentos, a fim de colaborar com a atuação nesse âmbito.

A segurança dos praticantes é um conhecimento primordial para esses profissionais, visto que o risco é uma característica inseparável dessas modalidades. Segundo Buckely e Uvinha (2011), as medidas de gestão de risco podem ser divididas de forma útil em seis grupos: comerciais, legais, médicas, operacionais, físicas e sociais. São conhecimentos amplos que exigem uma formação completa desses profissionais.

Na mesma direção, Carnicelli-Filho (2010, p. 285, tradução nossa) enfatiza que "todas as atividades outdoors requerem guias especializados que sejam capazes de minimizar os riscos inerentes à natureza dessas modalidades"11. Além dos conhecimentos específicos de domínio do lazer, os profissionais precisam se apropriar de uma instrução sobre primeiros socorros e possíveis ataques de animais peçonhentos.

A atração que o meio natural exerce sobre as pessoas foi perceptível durante toda a pesquisa de campo e merece algumas considerações concernentes às características do ser humano líquido, como discutido por Bauman $(2001 ; 2008)$. A "busca pela natureza" que, em tempos remotos, estava associada à descoberta e, ao mesmo tempo, à possibilidade de se encontrar riquezas, atualmente parece envolver, além desses aspectos, uma tentativa de legitimação da própria existência. Muitas vezes, já não se encontra conforto e prazer no cotidiano; a procura pelo "risco" nas experiências de lazer na natureza transforma-se em um jogo contra a morte, ou, nas palavras de Le Breton (2009, p. 162), "assume-se um risco de perecer ao se colocar com a própria vida em um dos pratos da balança”.

11. Original: "All these activities require specialized guides whose job it is to try to minimize the risk factors that are inherent in the nature of the activity." 
Os profissionais que atuam nas experiências de lazer na natureza, além de utilizarem essa atração pelo risco como forma de marketing, também foram sujeitos dessa atratividade e continuam em contato com tais atividades pelo mesmo motivo: seja na prática de mountain bike, seja na escalada, o desafio de se colocar em situação de perigo foi o componente primordial para a escolha do trabalho, e, nesse aspecto, os entrevistados frequentemente acabam por desconsiderar outros questionamentos importantes que circundam suas práticas.

Durante a pesquisa, percebeu-se uma forte ligação entre as experiências de lazer na natureza que necessitam de aparatos extras (por exemplo, bicicleta, jipes, instrumentos para alpinismo, entre outros) e a busca pelo risco. Esses artefatos de alto custo proporcionam uma segurança controlada em diversas práticas e, ao mesmo tempo, possibilitam atingir grandes velocidades e sensações "extremas". Quando um praticante se aproxima dos meios naturais carregado de instrumentos, o que transparece não é uma interação com o ambiente; ao contrário, emerge dessa relação uma espécie de confronto, desafio, combate.

Os profissionais que atuam nesse campo e que, ao mesmo tempo, são atraídos por esse tipo de emoção, precisam refletir criticamente sobre esses aspectos. No momento em que o ambiente natural é encarado como um adversário, ganha-se em "velocidade" e "adrenalina"; por outro lado, perdem-se outras possibilidades de interação com a natureza, principalmente quanto ao despertar da consciência ambiental. Na observação de campo das modalidades de mountain bike e escalada, essas características parecem evidentes. Nesse sentido, ganham importância os profissionais que pretendem engajar-se com a educação ambiental. Muito mais que simples "acompanhantes de trilhas", tais profissionais podem exercer um papel relevante na aquisição de uma consciência ambiental dos praticantes (LIMA, 2016).

As experiências de lazer na natureza, assim como em outros ambientes, passaram a incorporar as características inerentes aos grandes centros urbanos, tais como: competitividade, alta velocidade, efemeridade, individualismo, consumismo, entre outros. $\mathrm{O}$ ambiente natural que supostamente poderia ser um convite ao silêncio, à contemplação e à preservação tem sido utilizado como prolongamento da "selva de pedras", reproduzindo um ritmo de vida frenético regido pelo medo. Embora exista um movimento de retorno à natureza, principalmente como opção de lazer, nem sempre esse regresso é sinônimo de educação ambiental ou despertar de novas sensibilidades (PEREIRA; MYKLETUN, 2012). Frequentemente, novos obstáculos a serem ultrapassados e vencidos são almejados e, como consequência, a lógica do "quanto mais alto e rápido, melhor" torna-se o objetivo das práticas.

A influência da busca pelo risco, pela excitação e pela adrenalina é tão forte que até mesmo os conceitos acadêmicos que tentam definir essas experiências tendem à utilização desses termos. Tenta-se caracterizar essas atividades pelas emoções que podem proporcionar e, de maneira geral, acaba-se englobando todas as modalidades em uma única definição. Talvez fosse necessário diferenciar aquelas que estão mais associadas ao risco e aquelas que podem remeter à contemplação e à interação com o meio ambiente.

Embora as experiências de lazer na natureza mais comercializadas sejam as que possuem o "perigo" como pano de fundo, outras possibilidades também ganham espaço. Na pesquisa de campo foram analisadas experiências de observação de aves e trekking de longa duração e, diferentemente das outras, essas duas atividades indicaram valorização de um ritmo menos acelerado, sugerindo uma 
interação mais interessante entre ser humano e natureza, sem necessidade de aparatos extras para o seu desenvolvimento.

Os profissionais envolvidos nessas experiências de lazer evidenciaram maior sensibilidade no que tange à degradação do meio ambiente e à utilização dessas vivências como potencializadoras de consciência ambiental. No caso dos profissionais que atuam com a observação de aves, percebeu-se a preocupação quanto ao número de visitantes, à forma como acontece a aproximação para com os animais e, principalmente, quanto ao futuro dessa atividade de lazer perante as mudanças climáticas extremas. Já no caso dos guias de turismo que atuam com o trekking de longa distância no vilarejo Lapinha da Serra, essa preocupação também foi percebida, alcançando outros questionamentos, tais como: conduta dos praticantes, correta utilização da água dos rios, valorização dos habitantes locais, entre outros.

Quando se pensa em consciência ambiental e mudança de comportamento, certamente esses aspectos não são suficientes. No entanto, comparando-se a atuação profissional, de um lado, na observação de aves e trekking e, do outro, nas atividades de mountain bike e escalada, uma grande diferença foi constatada nesta pesquisa. Os profissionais dessas duas últimas experiências de lazer na natureza, embora tenham enfatizado em seus discursos e práticas alguns comportamentos "ecologicamente corretos", não chegaram a colocar tais questões como prioritárias. Assim, os aspectos ambientais ficam aquém dos aspectos técnicos e competitivos, mais valorizados pelos praticantes dessas atividades.

Nesse aspecto, tais observações possuem certas similaridades com a pesquisa realizada por Pereira e Mykletun (2012) com guias de turismo na região da Floresta Amazônica. Segundo os autores, a atuação desses profissionais se resume a acompanhar os praticantes pelas trilhas, sem que uma interpretação ecológica local seja perceptível.

Experiências que requerem maior sensibilidade e que, em certos aspectos, são desenvolvidas de maneira mais lenta e contemplativa parecem estar na contramão da lógica atual, baseada no controle de variáveis e na otimização do tempo. Assim como a chamada indústria cultural privilegia lazeres que, geralmente, exigem pouca reflexão e crítica, diversas experiências de lazer na natureza podem seguir essa mesma direção. Experiências como bungee jump, base jump e paraquedismo, entre outros, proporcionam uma grande descarga emocional em um tempo relativamente mínimo e, simultaneamente, requerem gastos substanciais para que sejam realizadas. Na maioria das vezes, essas experiências acontecem em cenários naturais belíssimos, onde a natureza, mais uma vez, é puro "palco" de luxo. Nesse aspecto, Park (2006) faz uma severa crítica ao nomear a Nova Zelândia a atual Disneylândia dos esportes radicais, de "país teatro".12

Na pesquisa de campo, foi perceptível a dificuldade dos praticantes oriundos dos centros urbanos em observar, sentir e decifrar os sinais do meio ambiente. Entretanto, o trecho a seguir evidencia como a convivência com os ambientes naturais pode ser transformadora:

A maioria dos visitantes retorna outras vezes para a Lapinha da Serra. Depois da primeira visita, as pessoas normalmente começam a respeitar mais a natureza, a não jogar lixo nas ruas e, até mesmo, fazer menos barulho. Quando nós observamos

12. Traduzido do original: "Theatre Country” (Park, 2006). 
alguém jogando lixo ou entrando na cidade com trajes de banho, falamos com eles na mesma hora. Tem gente que já respeita, mas tem gente que vem pela primeira vez e não está nem ligando para estas coisas. (Entrevistado 10)

As experiências de lazer na natureza mediadas por profissionais poderiam desafiar, cada vez mais, a visão dualista entre natureza e cultura que se instalou principalmente na parte ocidental do globo. No atual posicionamento das pessoas em relação à natureza (isto é, fora dela) pouco se pode avançar nas discussões sobre o meio ambiente. Verifica-se, assim, um afastamento dos paradigmas simplificadores do passado, da disjunção entre ser humano e natureza, como também a redução do meio ambiente em relação ao próprio sujeito.

Na tentativa de não exceder para um romantismo utópico, sabe-se que quase todas as ações voltadas para a diminuição desse distanciamento acabam fracassando. Por isso, espera-se que possam ser construídas novas formas e sensibilidades em relação à natureza por meio do despertar de sentidos, incorporações e sensualidades que ainda necessitam ser exploradas. Para além do puro "risco", existem outras perspectivas que poderiam estar presentes na formação, na atuação dos sujeitos das experiências de lazer na natureza e nos textos daqueles que pretendem contribuir com a discussão acadêmica da área.

Outro aspecto interessante, diretamente relacionado à degradação ambiental, é a prática minerária no estado de Minas Gerais, a qual se encontra, principalmente, nos entornos onde se realizou a pesquisa de campo. Dada a relação direta entre extração minerária e degradação do meio ambiente, poderiam ter sido feitas menções a respeito da temática durante as experiências de lazer na natureza, levando os participantes a questionamentos quanto à utilização da natureza, o aumento no número de praticantes de atividades de ecoturismo, conflitos territoriais etc. Em grande parte das experiências analisadas, porém, isso não ocorreu, o que pode ser um indício da normalização de práticas nocivas ao meio ambiente.

Observou-se, no trabalho de campo, a influência direta das questões relativas à mineração na vida dos cidadãos dos vilarejos estudados. Embora a discussão sobre a extração minerária esteja presente na vida dessas pessoas, uma visão mais crítica de tal atividade econômica - seja no diálogo com os moradores, seja no discurso dos profissionais do lazer na natureza -, ainda permanece incipiente. Tanto os moradores desses locais quanto os profissionais que atuam nessas regiões poderiam provocar algumas indagações a respeito do tema, o que não foi detectado nas conversas informais nem no desenvolvimento das experiências de lazer na natureza.

Durante a observação de campo das modalidades de mountain bike, escalada e trekking de longa distância, as experiências aconteceram nas imediações de áreas de mineração, e pouco se discutiu sobre a temática. Os profissionais que atuam nas experiências de mountain bike mencionaram a questão de maneira pontual e demonstraram preocupação quanto ao desenvolvimento da atividade minerária, chamando atenção sobretudo para a diminuição dos ambientes propícios para a realização da modalidade que praticam. Já os profissionais que atuam com a escalada e os guias de trekking da região da Lapinha não abordaram a questão. Os guias de turismo, por sua vez, demonstraram certa satisfação com o desenvolvimento da mineração, visto que o aumento no número de praticantes dessas experiências poderia estar ligado à exploração mineral na região. 
O impacto relacionado ao número de praticantes de atividades de lazer em áreas naturais foi assunto constante durante as entrevistas realizadas no trabalho de campo. Os profissionais que participaram da pesquisa, exceto os que atuam com observação de vida selvagem, pontuaram o quão difícil é sobreviver economicamente do turismo na natureza. Se, por um lado, constatou-se que existe preocupação em relação ao número de pessoas presentes em cada passeio, por outro, um número maior de clientes possibilita maior lucratividade.

Na mountain bike, na escalada e no trekking de longa duração, um grupo precisa ser composto por, no mínimo, três pessoas e, no máximo, doze. No entanto, sabe-se que quanto maior o número de pessoas, menor poderá ser a interação com o meio ambiente e maior a necessidade da contratação de novos profissionais. No caso da observação de vida selvagem, existe um número máximo que não deve exceder as cinco pessoas, e sempre realiza-se a viagem com pelo menos dois guias. A prioridade desses profissionais é possibilitar uma maior integração entre ser humano, fauna e flora; para isso, limitar o número de pessoas é primordial. Entretanto, é possível cobrar um preço mais elevado desses praticantes, pois, como foi observado no trabalho de campo, na maioria das vezes, estes possuem um poder aquisitivo maior que o de praticantes de outras modalidades. ${ }^{13}$

Levando-se em consideração as análises obtidas nesse estudo, a tendência mundial é que as experiências especializadas de turismo na natureza tenham um custo cada vez maior. No Brasil, isso já é perceptível em lugares como Bonito $^{14}$ e Fernando de Noronha ${ }^{15}$, nos quais o custeio da viagem pode exceder o de uma visita a países estrangeiros. No entanto, quando se pensa em experiências menos comerciais, como o trekking observado nesta pesquisa ou a prática da escalada e de mountain bike, o custo ainda é pequeno e pode atrair um segmento maior da população. Contudo, algumas regras precisam ser cumpridas no que diz respeito ao número de clientes e a possíveis condutas geradoras de degradação ambiental.

Considerando-se o objetivo final de algumas atividades de despertar sensibilidade naqueles que vivenciam experiências na natureza, é comum a ideia de que só seria possível uma interação profunda entre ser humano e natureza em ambientes paradisíacos. Contudo, o ambiente não é o responsável por essa mudança de sensibilidade, e sim o próprio indivíduo. Mesmo vivendo nos grandes centros urbanos, essa consciência ecológica torna-se primordial no contato com o ambiente externo, com as outras pessoas, no uso da água, no tratamento do lixo, na utilização da energia, na mudança de comportamento de maneira geral. Nesse aspecto, a presença de profissionais qualificados torna-se crucial quando percebemos uma preocupação ambiental em seu discurso. "Tais profissionais podem proporcionar uma aproximação única entre os praticantes e os aspectos relacionados à ecologia", como destaca Lima (2016, p. 18).

Nesse contexto, é preciso que haja maior valorização de mudanças que possibilitem hábitos e comportamentos menos consumistas. Assim como vários setores econômicos, o turismo na natureza também tem priorizado experiências

13. Informações obtidas ao longo da pesquisa de campo (Notas do Caderno de Campo).

14. Município brasileiro da região Centro-Oeste, situado no estado de Mato Grosso do Sul.

15. Arquipélago brasileiro situado no estado de Pernambuco, formado por vinte e uma ilhas. 
comerciais e de pouco apelo educativo. Existe a necessidade de se explorar economicamente todos os ambientes naturais da Terra, desde o deserto mais seco do mundo até a montanha mais alta. 0 que transparece é a busca desenfreada pelo "inexplorado", que se encontra sempre do lado de fora, e, em contrapartida, a dificuldade em "explorar" valores humanos, tão necessários no momento presente.

\section{CONSIDERAÇÕES FINAIS}

Esta pesquisa sobre atuação profissional no contexto do ecoturismo evidenciou que os profissionais investigados possuem algumas características em comum. Todos, de alguma forma, estabeleceram na infância e a partir da convivência com os pais uma "paixão" pela natureza e, consequentemente, pela proximidade com os ambientes naturais. Desenvolveram essa sensibilidade ao longo da adolescência (organizando acampamentos, realizando viagens de lazer, "fugindo" dos grandes centros urbanos) e cultivaram-na ao longo da vida.

Embora inúmeras dificuldades permeiem esse campo de atuação profissional, os entrevistados continuam atuando com essas experiências, seja no trabalho, seja no lazer, e todo esse envolvimento possui uma única explicação: o gosto pela profissão e pela aproximação com a natureza. Mesmo que sejam passíveis de críticas e instiguem reflexões, esses aspectos foram constantes no desenvolvimento desta pesquisa.

Foi constatado também o cuidado dos profissionais que atuam com o ecoturismo em estabelecer um olhar menos dicotômico quando estão se relacionando com os praticantes. Isso é relevante porque muitas vezes, nesse setor, são reforçados valores que fortalecem e perpetuam a distinção entre o ser humano e a natureza, por exemplo.

Atualmente, constatamos que tanto o ecoturismo quanto outras atividades de lazer em áreas naturais estão atravancados pelo mito da natureza intocada. Áreas protegidas favorecem populações urbanas visitantes para a realização dessas "aventuras", sem garantias de retorno e melhorias para as populações locais,

em sua grande maioria iletradas, geograficamente isoladas, sem poder político, mas que por séculos, por seu modo de visa, são responsáveis pela conservação do chamado "mundo natural". Isso é mais grave quando se sabe que a permanência dessa população tradicional em seus habitats pode levar, de forma mais adequada, à conservação da biodiversidade. (DIEGUES, 1996, p. 68)

Uma visão extremista pode reforçar a crença de que as pessoas interessadas em atividades de lazer em áreas verdes são visitantes ingênuos, puros e separados daquele contexto. Essa separação abissal pode reafirmar o pensamento generalizado de que a função da natureza é de simples fornecimento de recursos naturais, sem que se tenha consciência da finitude dessas riquezas e, principalmente, da necessidade de preservação.

A atuação profissional com atividades de lazer na natureza está igualmente exposta às condições de reprodução social, uma vez que o movimento mais abrangente do ecoturismo é permeado por relações produtivas e mercantis. Portanto, tal movimento de regresso à natureza é ideológico e pode atuar tanto em 
nome da conservação ambiental e da transformação social quanto em nome da depredação ou da alienação.

Dessa forma, uma melhor compreensão da dinâmica entre profissionais, campo de trabalho e praticantes poderia auxiliar no desenvolvimento de um olhar crítico decorrente das experiências de educação ambiental proporcionados pelo ecoturismo. Compreensão, esta, que pode gerar melhorias na qualidade do trabalho nas diversas modalidades de turismo ecológico.

Concluindo, ao compartilharem o trabalho com experiências na natureza, o turismo e o lazer carecem de novas pesquisas e aprofundamentos que englobem o dia a dia dos profissionais que atuam com o ecoturismo, contribuindo para aprimorar os conhecimentos sobre esse campo. Espera-se, assim, que a investigação realizada represente um ponto de partida para outros estudos sobre a temática, instigando novos olhares sobre o turismo e o lazer em áreas naturais.

\section{REFERÊNCIAS}

ARNOULD, E.; PRICE, L.; TIERNEY, P. Communicative staging of the wilderness service scape. The Service Industries Journal, [s. l.], v. 18, p. 90-115, 1998.

BARRETTO, M. As ciências sociais aplicadas ao turismo. In: SERRANO, C.; BRUHNS, H. T.; LUCHIARI, M. T. D. P. Olhares contemporâneos sobre o turismo. Campinas: Papirus, 2000. p. 17-36.

BAUMAN, Z. Modernidade líquida. Rio de Janeiro: Zahar, 2001.

BEATTY, J. E.; TORBET, W. R. The false duality of work and leisure. Journal of Management Inquiry, [s. l.], v. 12, n. 3, p. 239-252, 2003.

BERNARDINO, C. R.; ISAYAMA, H. F. Lazer e turismo: análise de currículos de cursos de graduação em turismo de Minas Gerais. Licere, Belo Horizonte, v. 9, n. 2, p. 8-23, 2006.

BRASIL. Ministério da Indústria, do Comércio e do Turismo; Ministério do Meio Ambiente, dos Recursos Hídricos e da Amazônica Legal. Diretrizes para uma Política Nacional de Ecoturismo. Brasília, DF: Embratur, 1994.

BRUHNS, H. O ecoturismo e o mito da natureza intocada. Acta Scientiarum: Human and Social Sciences, Maringá, v. 32, n. 2, p. 157-164, 2010.

BRUHNS, H. T.; MARINHO, A. Ritos e rituais nas viagens à natureza. Revista Brasileira de Ecoturismo, São Paulo, v. 5, n. 1, p. 87-112, 2012.

BUCKLEY, R.; UVINHA, R. R. Turismo de Aventura: gestão e atuação profissional. Rio de Janeiro: Elsevier, 2011.

CAMARGO, L. O. L. Sociologia do lazer. In: ANSARAH, M. G. Turismo: como aprender, como ensinar. 2. ed. São Paulo: Senac, 2001. v. 2.

CARNICELLI-FILHO, S. Rafting guides: leisure, work and lifestyle. Annals of Leisure Research, Otago, v. 13, n. 1, p. 282-297, 2010.

CASTILHO, C. T. Lazer na natureza e atuação profissional: discursos e práticas contemporâneas. 2013. Dissertação (Mestrado em estudos do Lazer) - Universidade Federal de Minas Gerais, Belo Horizonte, 2013.

CORIOLANO, L. N. M. T. O turismo nos discursos, nas políticas e no combate à pobreza. São Paulo: Annablume, 2006.

DIEGUES, A. C. $O$ mito da natureza intocada. São Paulo: Hucitec, 1996. 
DUMAZEDIER, J. Towards a society of leisure. London: Lutterworth Press, 1967.

DUNCAN, T. Transient workers in Queenstown and Whistler. In: HIGHAN, J.; HINCH, T. Sport and tourism: globalization, mobility and identity. Oxford: Elsevier, 2009. p. 173-174.

EMERSON, R. W. Nature. In: COOK, R. L. Selected prose and poetry. New York: Holt, Rhinehart \& Winston, 1836.

FARIA, J. S. A. Análise da temática do lazer em artigos publicados em periódicos nacionais e internacionais do turismo (2006-2010). 2012. 104 f. Dissertação (Mestrado em Estudos do Lazer) - Escola de Educação Física, Fisioterapia e Terapia Ocupacional, Universidade Federal de Minas Gerais, Belo Horizonte, 2012.

GASTAL, S.; MOESCH, M. M. Turismo, políticas públicas e cidadania. São Paulo: Aleph, 2007.

GERSHUNY, J. Changing times: work and leisure in postindustrial society. Oxford: Oxford University Press, 2000.

GOMES, C. L. Lazer como necessidade humana e dimensão da cultura. Revista Brasileira de Estudos do Lazer, Belo Horizonte, v. 1, n. 1, p. 3-20, 2014.

GOMES, C. L.; ISAYAMA, H. F. (Orgs.). O Direito Social ao Lazer no Brasil. Campinas: Autores Associados, 2015.

GOMES, C. L. et al. Inserção do lazer no contexto da pós-graduação stricto sensu em turismo/ hospitalidade no Brasil. Caderno Virtual de Turismo, Ilha do Fundão, v. 8, n. 3, p. 54-66, 2008.

JAMAL, T.; EVERETT, J.; DANN, G. M. Ecological rationalization and performative resistance in natural area destinations. Tourist Studies, [s. l.], v. 3, n. 2, p. 143-169, 2003.

LAVILLE, C.; DIONNE, J. A construção do saber: manual de metodologia da pesquisa em ciências humanas. Porto Alegre: Artmed, 1999.

LE BRETON, D. Condutas de risco: dos jogos de morte ao jogo de viver. Campinas: Autores Associados, 2009.

LIMA, I. B. Pivotal role of tour guides for visitors' connection with nature: conceptual and practical issues. International Journal of Humanities and Applied Sciences, [s. l.], v. 5, n. 1, p. 18-22, 2016.

MINAYO, M. C. S. O desafio do conhecimento: pesquisa qualitativa em saúde. São Paulo: Hucitec, 2010.

MOESCH, M. M. Turismo e lazer: conteúdos de uma única questão. In: MARCELLINO, N. C. Formação e desenvolvimento de pessoal em lazer e esporte. Campinas: Papirus, 2002.

MOSS, S. A bird in the bush: a social history of birdwatching. London: Aurum, 2005.

PANOSSO NETTO, N. O que é turismo. São Paulo: Brasiliense, 2010.

PARK, G. Theatre country: essays on landscape and Whenua. Wellington: Victoria University Press, 2006.

PELLEGRINI FILHO, A. Ecologia, cultura e turismo. Campinas: Papirus, 1993.

PEREIRA, E. M.; MYKLETUN, R. Guides as contributors to sustainable tourism? A case study from the amazon. Scandinavian Journal of Hospitality and Tourism, [s. l.], v. 12, n. 1, p. 74-94, 2012.

PIMENTEL, G. G. A. Atuação profissional em recreação na natureza. In: MARINHO, A.; UVINHA, R. R. Lazer, esporte, turismo e aventura: a natureza em foco. Campinas: Alínea, 2009. p. 169-197.

REJOWSKI, M. [Orelha do livro]. In: GOMES, C. L.; PINHEIRO, M.; LACERDA, L. Lazer, turismo e inclusão social: intervenção com idosos. Belo Horizonte: UFMG, 2010. Disponível 
em: <http://www.esporte.gov.br/arquivos/sndel/esporteLazer/cedes/lazerTurismoInclusaoSocial.pdf>. Acesso em: mar. 2016.

SCHOR, J. B. The overworked American: the unexpected decline of leisure. New York: Basic Books, 1992.

SEABRA, G. F. Ecos do turismo: o turismo ecológico em áreas protegidas. Campinas: Papirus, 2001.

SERRANO, C. A educação pelas pedras: uma introdução. In: SERRANO, C. A educação pelas pedras: ecoturismo e educação ambiental. São Paulo: Chronos, 2000. p. 7-24.

. Uma introdução à discussão sobre Turismo, Cultura e Ambiente. In: SERRANO, C; BRUHNS, H. T. Viagens à natureza: turismo, cultura e ambiente. Campinas: Papirus, 1997. p. 11-25.

SERRES, M. Le concept de nature. Études, [s. 1.], v. 400, p. 67-73, 2004.

SOUZA, T. R. Análise sobre estudos do lazer em mestrados em turismo e hospitalidade no Brasil (2001-2007). 2011. 150 f. Dissertação (Mestrado em Estudos do Lazer) - Escola de Educação Física, Fisioterapia e Terapia Ocupacional, Universidade Federal de Minas Gerais, Belo Horizonte, 2011.

STEBBINS, R. Quando o trabalho é essencialmente lazer. Revista Brasileira de Estudos do Lazer, Belo Horizonte, v. 1 n. 1, p. 42-56, 2014.

TAVEIRA, M.; GONÇALVES, S. Lazer e turismo: análise teórico-conceitual. In: CONGRESSO LATINO-AMERICANO DE INVESTIGAÇÃO TURÍSTICA, 5., 2012, São Paulo. Anais eletrônicos... São Paulo: USP, 2012. Disponível em: <http://gtci.com.br/congressos/congresso/2012/pdf/eixo10/Taveira_Goncalves.pdf>. Acesso em: 10 out. 2015.

TELES, R. M. S. (Org.). Turismo e meio ambiente. Rio de Janeiro: Elsevier, 2011.

VEBLEN, T. The theory of the leisure class. New York: Macmillan, 1899.

WALLE, A. H. Pursuing risk or insight: marketing adventures. Annals of Tourism Research, Amsterdam, v. 24, n. 2, p. 265-289, 1997.

WEARING, S.; NEIL, J. Ecoturismo: impactos, potencialidades e possibilidades. Barueri: Manole, 2001.

ZAGO, N. A entrevista e seu processo de construção: reflexões com base na experiência prática de pesquisa. In: ZAGO, N.; CARVALHO, M. P.; VILELA, R. A. T. Itinerários de pesquisa: perspectivas qualitativas em sociologia de educação. Rio de Janeiro: Lamparina, 2003. p. 287-309. 